Teaching \& Learning (2011) 6(1), 62-73

\title{
An Analysis of Correlations among Secondary School Physical and Health Education Teachers' Beliefs and Instruction
}

\author{
DR. KEN R. LODEWYK \\ Brock University
}

\begin{abstract}
This paper reports the underlying theory, methods, results, and conclusions of a study investigating relations among 26 ninth and/or tenth grade physical education teachers' age, beliefs about knowledge, ability, and the need for cognition, and their preferred instructional methods and aims. Each has been associated with a variety of outcomes in physical education. Results revealed that most teachers preferred a relativist worldview and more highly valued curricular outcomes such as fitness, character, and community, to skill and knowledge. More autonomous practices were associated with a contextualist worldview and to a high belief in the need for cognition, and negatively to a realist perspective and to direct teaching. Finally, a contextualist worldview, a higher need for cognition, and higher incremental ability conceptions, and lower entity ability conceptions were statistically correlated to lower (more availing) beliefs in the simple-integration and stable-expertise of knowledge. Implications for scholars and practitioners are asserted.
\end{abstract}

\section{Introduction}

Social cognitive theory asserts the critical interplay of personal, behavioural, and environmental factors on students' self-determination and achievement by influencing students' critical needs, such as their perceptions of competence, autonomy, and relatedness (Bandura, 1986; Ryan \& Deci, 2000). For example, there is growing awareness in the educational literature that teachers' beliefs about knowledge and ability influence how they teach, but also how their students believe, define, and judge their own knowledge and ability (Dweck, 2002; Rovegno, 2003). Little research has been conducted on the beliefs, aims, and instructional practices of physical education teachers, so this study explores correlations between physical and health education (PHE) teachers' age, beliefs about knowledge, ability, and the need for cognition, and their preferred instructional methods and aims. 


\section{Beliefs about Knowledge, Ability, and the Need for Cognition}

Epistemology is the study of the nature of knowledge and how one knows. Educational research into epistemology has investigated personal beliefs about the structure of knowledge (e.g., isolated bits of reality or ambiguous individually-perceived concepts), from where it comes (e.g., authorities, reasoning, experimentation, or through experience), how much it can change (e.g., incremental or stable), and how it can be attained (e.g., self-regulated or environmentally conditioned). Two core frameworks within beliefs about epistemology that will be investigated in this study are epistemological worldviews (Schraw \& Olafson, 2002) and epistemological beliefs (Hofer \& Pintrich, 2002).

Epistemological worldviews are generalized intellectual belief systems about the nature of knowledge, and each has implications on how individuals can know and learn (Schraw \& Olafson, 2002). Schraw and Olafson (2002) conceptualized and studied three epistemological worldviews: realism, relativism, and contextualism. Each has demonstrated consistency across various educational domains and represents a relatively unique approach to reality, knowledge, and pedagogy (for examples, see Table 1). Epistemological beliefs have emerged from research in various educational domains (Hofer \& Pintrich, 2002), including physical education (Lodewyk, 2009b). Two emerging dimensions are the simplicity (knowledge as uncomplicated and isolated) and stability (knowledge as unchanging) of knowledge. These also have implications on practice. Less-sophisticated (naïve) epistemological beliefs have been associated with, for example, less frequent use of a rather indirect teaching method (Lodewyk, 2009a) in teachers and more superficial reflective judgments and lower academic performance in students (Hofer \& Pintrich, 2002). Believing that knowledge is simple and or stable has also been linked to less belief in the need for cognition - the degree one uses and enjoys using their cognition to complete a task (Lodewyk, 2009a). Further, perceiving a high need for cognition is linked to improved resolution of ambiguities in problem situations (Kardash \& Scholes, 1996), and a stronger preference for using a rather indirect teaching method in prospective physical educators (Lodewyk, 2009a).

Teachers' instructional goals and practices (e.g., relationships with particular students) are partially dependent on how they conceive of students' ability (Dweck, 2002). For example, teachers either believe that ability can be learned and developed through concentrated hard work - an incremental ability conception (IAC) - or that ability is relatively unchangeable and 
simply reliant on genetic factors - an entity ability conception (EAC). Related research with physical education students has reported that those endorsing an IAC tend to use self-regulatory strategies more advantageously (Ommundsen, 2003), show more enjoyment (Biddle, Wang, Chatzisarantis, \& Spray, 2003), and believe that effort can mediate ability to enable one to attain his or her potential (Li, Lee, \& Solmon, 2005).

Table I

A Comparison of Three Beliefs across Three Epistemological World Views

\begin{tabular}{|l|l|l|l|}
\hline & \multicolumn{1}{|c|}{ Realist Worldview } & Contextualist Worldview & \multicolumn{1}{|c|}{ Relativist Worldview } \\
\hline $\begin{array}{l}\text { Beliefs about } \\
\text { Ontology: The } \\
\text { nature of reality and } \\
\text { standards for } \\
\text { judging truth. }\end{array}$ & $\begin{array}{l}\text { Objective reality; } \\
\text { Truth corresponds to } \\
\text { external reality and } \\
\text { universal standards. }\end{array}$ & $\begin{array}{l}\text { No objective reality; } \\
\text { Consensual truth using } \\
\text { negotiated standards. }\end{array}$ & $\begin{array}{l}\text { No objective reality or } \\
\text { consensual truth; } \\
\text { Personal truth that is } \\
\text { subjective in nature using } \\
\text { idiosyncratic standards. }\end{array}$ \\
\hline $\begin{array}{l}\text { Beliefs about } \\
\text { npistemology: The } \\
\text { knowledge and } \\
\text { knowing. }\end{array}$ & $\begin{array}{l}\text { Objective and } \\
\text { universal; Independent } \\
\text { of knower; Relatively } \\
\text { unchanging }\end{array}$ & $\begin{array}{l}\text { Situational; } \\
\text { Adapted by knower to fit } \\
\text { contextual demands; } \\
\text { Changes consensually }\end{array}$ & $\begin{array}{l}\text { Subjective and particular; } \\
\text { Unique to knower; } \\
\text { Highly changeable }\end{array}$ \\
\hline $\begin{array}{l}\text { Beliefs about } \\
\text { Pedagogy }\end{array}$ & $\begin{array}{l}\text { Transmission; } \\
\text { Teacher-centered; } \\
\text { Expert dissemination } \\
\text { to passive but self- } \\
\text { regulating recipients } \\
\text { with little peer role. }\end{array}$ & $\begin{array}{l}\text { Transactional; } \\
\text { Student and group- } \\
\text { centered; } \\
\text { Supportive co- } \\
\text { collaborator and co- } \\
\text { participant with self- } \\
\text { regulating students and } \\
\text { collaborative peers. }\end{array}$ & $\begin{array}{l}\text { Autonomous; } \\
\text { Individual-centered; } \\
\text { Active facilitator } \\
\text { (feedback); } \\
\text { Students are active (self- } \\
\text { constructors with minimal } \\
\text { peer importance. }\end{array}$ \\
\hline
\end{tabular}

Note: Adapted from Schraw and Olafson, 2002.

\section{Instruction}

Instructional methods in physical and health education tend to be conceptualized as somewhere between the extremes of direct or indirect approaches (Metzler, 2000). Direct teaching is a more traditional teacher-centered method in which the teacher transmits knowledge to more passive learners, structures and requires students to perform practice tasks to maximize trials, and provides high quantities of specific and personalized feedback to students. Though related, Teaching Games for Understanding (TGfU) is a more indirect instructional approach to teaching that emphasizes facilitating rather than dictating content, so that students actively construct their understanding and learning (Oslin \& Mitchell, 2006). TGfU lessons typically 
utilize authentic game-like activities to maximize learning transfer, while encouraging small groups of students to think about and share useful tactics, and to design and implement modifications to activities (i.e., rules, dimensions), to make them more effective.

Learners who perceive that their teacher understands them, provides them with choices, listens and tries to understand how they would like to do things, demonstrates confidence in their ability to succeed, and invites them to ask questions - all part of a concept called perceived autonomy support - tend to be more self-determined, are rated higher in effort and perseverance by their physical education teachers (Standage, Duda, \& Ntoumanis, 2006), are more prone to future participation in optional physical education (Ntoumanis, 2005) and to being more autonomously-motivated for leisure-time physical activity (Haggar \& Chatzisarantis, 2007).

Based on the evidence of need for this study, it will address the following three central research questions: (1) Do PHE teachers more highly value teaching for character, skills, community, play, knowledge, or fitness? (2) Do PHE teachers prefer teaching PHE using more direct or indirect (TGfU) methods and does age have any relationship with this preference? (3) How does their preferred instructional method relate to their autonomous-supportive practices and to their beliefs about knowledge (epistemological worldviews and beliefs), need for cognition, and ability conceptions?

\section{Methods}

The sample consisted of 26 volunteer teachers (all Caucasian; 13 males and 13 females; $\mathrm{M}_{\mathrm{age}}=41.3$ ) of ninth and tenth-grade physical education, representing 13 secondary schools from a school district in south-central Canada. Each participating teacher completed a Demographic Questionnaire that assessed age, years of teaching experience, and preferred instructional aims (one item for each with the question stem: "In PE, teaching movement skills is my top goal.”). In addition, teachers completed six previously-validated Likert-style questionnaires (on a 5-point scale ranging from "strongly disagree" to "strongly agree") totalling 40 items along with several others intended for use in another study. The wording of each of the items was revised, if necessary, for use in PHE teachers. For example, wherever necessary "PHE" and "teachers" was inserted to ensure the context of each item was teaching in PHE. Teachers completed the survey as students completed surveys for another study. In a few cases, 
teachers chose to complete them on their own time and mail them to the first author. Prior to providing their written consent and to completing the survey, teachers were informed about the purpose of the study, that there were no correct or incorrect answers, and that their responses would be kept confidential and anonymous.

\section{Beliefs about Knowledge, Ability, and the Need for Cognition}

Teachers' realist, contextualist, and relativist epistemological worldviews were assessed using three one-paragraph teaching vignettes (descriptions provided through a scenario) developed and validated by Schraw and Olafson (2002). Teachers were asked to read the vignettes, and then to allot points totalling 100 across the three vignettes, based on the extent that they agreed with each.

Items with high factor loadings $(n=10)$ from the 12-item Beliefs about Knowledge in Physical Education Questionnaire (BEPEQ) were used to assess teachers' epistemological beliefs. The BEPEQ was developed and validated by Lodewyk and Sullivan (2010). Seven items made up the Simple Integration of Knowledge (SIK) scale, whereas the Stable-Expert Knowledge (SEK) scale had 3 items. Teachers with high scores on SIK were more prone to believing that PHE knowledge in secondary physical education is clear, uncomplicated, and not highly integrated to other concepts inside or outside the domain. A sample SIK item is: "In my teaching, I try my best to link information across the many different learning activities in PE." High values for SEK likely believed that knowledge in PE is relatively unchanging and is agreed upon by experts. A sample SEK item is "All experts in PE understand PE in the same way."

The 12-item Conceptions of the Nature of Sport Ability II Questionnaire (CNAAQII) was used to assess beliefs about ability in physical education teachers. It has been validated for physical education (e.g., Lodewyk \& Sullivan, 2010; Ommundsen, 2003) and consists of six items tapping incremental ability conceptions (ability is self-regulated through effort; IAC) and six others for entity ability conceptions (ability is inherited and cannot be much altered with effort; EAC). An exemplary item for each is: "Even if a student tries, the level they reach in PE will change very little" (EAC), and "How good a student is in physical education will always improve if they work at it" (IAC).

The need for cognition was assessed using eight items (relevant and modified for physical education) from the previously validated 18-item Need for Cognition Questionnaire (Kardash \& 
Scholes, 1996). Individuals who score high in the need for cognition enjoy becoming engaged in challenging situations that require mental concentration and problem-solving. A sample item is "In PE, students should prefer trying to solve complex rather than simple problems."

\section{Instruction}

There were 13 items on the survey that provided information about instructional preferences. One item ("I usually use a teacher-controlled direct instructional method when I teach PE") assessed teachers' preference for using a more direct instructional style. Another item (reverse coded; "I rarely if ever use the Teaching Games for Understanding instructional method when I teach PE") did the same for the indirect method known as TGfU. Five items from the Learning Climate Questionnaire (LCQ) were used to assess PHE teachers' autonomous and/or supportive practices. Autonomy-supportive instruction (ASI) reflects the degree that teachers attempt to provide students with choices, listen and try to understand how students would like to do things, demonstrate confidence in students' abilities to succeed, and invites students to ask questions. The LCQ has been adapted, used, and validated for use in PHE revealing Cronbach's alpha ranging from .81 to .96 (Ntoumanis, 2005; Standage, et al., 2006). Three items comprised the autonomous-instruction (AI) scale and the other three items made up the supportiveinstruction (SI) scale. A sample item for AI is: "I feel that my physical education teachers provide me choices and options."

\section{Results}

Analysis of the data to meet the objectives of the study was performed by computing descriptive statistics (with no evidence of abnormal distributions), internal consistency reliability coefficients (Cronbach's alpha), and Pearson product-moment bivariate correlation coefficients. More advanced statistical procedures (e.g., multiple linear regressions) were not computable due to the size of the sample. These are presented in Tables I and II. One item for IAC and one for AS was dropped to enable internal consistency reliability coefficient for each scale $(.63-.82)$ that were satisfactory (Loewenthal, 1996). Descriptive statistics are provided in Table II and bivariate correlations are presented in Table III. 


\section{Teachers’ Age and Preferred Instructional Method and Aims}

Teachers had higher values for curricular outcomes such as fitness $(\mathrm{M}=3.50 ; \mathrm{SD}=.99)$, character $(\mathrm{M}=3.62 ; \mathrm{SD}=.85)$, and community $(\mathrm{M}=3.34 ; \mathrm{SD}=.75)$ than the development of skill $(\mathrm{M}=2.46 ; \mathrm{SD}=.81)$ and knowledge $(\mathrm{M}=2.19 ; \mathrm{SD}=.81)$. They also had a higher mean (more frequent use) for a direct $(\mathrm{M}=3.69 ; \mathrm{SD}=.62)$ than a less direct teaching model (TGfU; $\mathrm{M}$ $=2.92 ; \mathrm{SD}=.89$ ). There was a positive correlation between age and use of TGfU indicating that older teachers are related to more frequent use of TGfU.

Table II

Descriptive Statistics and Cronbach's Alpha $(\alpha)$

\begin{tabular}{|c|c|c|c|}
\hline Construct & $\alpha$ & $M$ & $S D$ \\
\hline Realist Epistemological Worldview (REW; \%) & - & 30.00 & 20.53 \\
\hline Contextualist Epistemological Worldview (CEW; \%) & - & 20.70 & 13.68 \\
\hline Relativist Epistemological Worldview (RLEW; \%) & - & 49.30 & 23.05 \\
\hline Direct Teaching (DT) & - & 3.69 & .62 \\
\hline Teaching Games for Understanding (TGfU) & - & 2.92 & .89 \\
\hline Autonomous Teaching (AT) & .64 & 4.05 & .41 \\
\hline Supportive Teaching (ST) & .68 & 3.90 & .63 \\
\hline Simple Integration of Knowledge (SIK) & .77 & 1.68 & .43 \\
\hline Stable Expert Knowledge (SEK) & .75 & 2.10 & .55 \\
\hline Need for Cognition (NC) & .69 & 3.57 & .40 \\
\hline Incremental Ability Conception (IAC) & .63 & 4.05 & .46 \\
\hline Entity Ability Conception (EAC) & .72 & 2.06 & .57 \\
\hline
\end{tabular}

Note: $\alpha$ absent in REW, CEW, RLEW, DT, and TGfU as they were single-item scales. 


\section{Relations among Instruction and Beliefs about Knowledge, Ability, and the Need for Cognition}

Results generally revealed a predominately relativist worldview (50\%) compared to realists (30.0\%) and contextualists (20.7\%). Bivariate correlations (see Table III) signalled that a contextualist epistemological worldview was significantly and inversely correlated to both the realist (-.81) and relativist (-.47) worldviews, and was statistically related to lower beliefs in simple-integration of knowledge (-.49) and to more frequent use of perceived autonomous practices with students (.56).

Higher incremental ability conceptions and need for cognition and lower entity ability conceptions were statistically correlated to more availing epistemological beliefs (lower simpleintegration of knowledge and stable-expert knowledge). More autonomous practices were associated with a high belief in the need for cognition (.42) and negatively to a realist perspective (-.66) and to direct teaching (-.41).

Table III

Bivariate (Pearson) Correlations $(p<.05)$

\begin{tabular}{|c|c|c|c|c|c|c|c|c|c|c|c|}
\hline & CEW & RLEW & DT & TGfU & AT & ST & SIK & SEK & $\mathrm{NC}$ & IAC & EAC \\
\hline REW & -.81 & & & & & -.66 & & & -.45 & & \\
\hline CEW & - & -.47 & & & .56 & & -.49 & & & & \\
\hline RLEW & & - & & & .44 & & .43 & & & & \\
\hline DT & & & - & & -.41 & & & & & & \\
\hline TGfU & & & & - & & & & & & & \\
\hline $\mathrm{AT}$ & & & & & - & & & & .42 & & \\
\hline ST & & & & & & - & & & & & \\
\hline SIK & & & & & & & - & .41 & -.37 & -.48 & \\
\hline
\end{tabular}


$\mathrm{NC}$

$\mathrm{IAC}$

EAC

Note: Realist Epistemological Worldview (REW), Contextualist Epistemological Worldview (CEW), Relativist Epistemological Worldview (RLEW), Direct Teaching (DT), Teaching Games for Understanding (TGfU), Autonomous Teaching (AT), Supportive Teaching (ST), Simple Integration of Knowledge (SIK), Stable Expert Knowledge (SEK), Need for Cognition (NC), Incremental Ability Conception (IAC), Entity Ability Conception (EAC).

\section{Discussion}

It seems prudent to acknowledge limitations of the study prior to asserting any potential implications from it. Although the results signalled that the measures for each construct were generally valid and reliable, several scale reliability coefficients were moderate (.60-.69) and some of them were assessed using only one item. The lower than ideal sample size pre-empted any advanced statistical procedures beyond correlations; hence, assertive causal or predictive inferences cannot be made. The results are also limited to these schools, teachers, and ethnicities similar to those represented in this study. Finally, other forms of data collection (e.g., qualitative measures) would be useful. It would also be useful for future studies to add more items to singleitem measures herein, and increase the number of participants.

Overall, the study supported many expected relationships based on theory and previous research with teachers. This study revealed that PE teachers more highly valued curricular outcomes such as fitness, character, and community than the development of skill and knowledge. This reinforces research reporting that secondary school physical educators' tend to value teaching for social responsibility (Behets \& Vergauwen, 2004). Interestingly, teachers placed less value on knowledge aims, despite the necessity for knowledge and cognitive processing in movement-oriented domains like PE (Dodds, Griffin, \& Placek, 2001). For example, compared to novices, skilled movers possess greater declarative and procedural knowledge, process information and strategically decide more rapidly, and free cognitive space in working memory by relying less on declarative than procedural knowledge (McPherson \& Kernoodle, 2003). Teachers may need to be convinced of the relative importance of knowledge 
in PE if they are to fully adapt to and implement more indirect instructional methods such as TGfU, which emphasizes comprehension of tactics in concert with movement, social, and problem-solving skills (Oslin \& Mitchell, 2006). More specifically, knowledge and proficiency in tactics, skills, and affect for various game conditions are fostered in TGfU, by stimulating students to be physically and mentally engaged in regulating their learning. Convincing PE teachers of the merits of TGfU may be necessary, as the use of a direct method was reported more than use of TGfU in this study. Such efforts may need to be more targeted at younger teachers since older aged teachers were prone to using more of TGfU in this study. Butler (2005) reports that TGfU is quite a novel approach for most PHE teachers, and that implementing it is slowed by the tendency of most teachers to "follow the path of least resistance." Butler adds that teachers who implement TGfU report favourable student responses, more engaging social interactions, and better integration of mind, movement, interpersonal relations, and feelings, all of which motivate them to continue with it.

Results generally revealed teachers were most supportive of a relativist worldview. The absence of a negative correlation between a realist and a relativistic worldview was surprising, although the significantly inverse correlation between those reporting a contextualist worldview and both the realist and relativist worldviews met theoretical expectations. In other words, a contextualist worldview tends to be theoretically more of a hybrid view between the more philosophically extreme realist and relativist positions (see Table I). This was also reflected in the study's finding that more autonomous practices were associated with a contextualist worldview and to a high belief in the need for cognition, and negatively to a realist perspective and to direct teaching. For example, contextualists may be more prone to instructing less directly and more autonomously, as they structure the learning environment to engage students to cognize and complete learning tasks collaboratively (Schraw \& Olafson, 2002).

A contextualist worldview, a higher need for cognition, and higher incremental ability conceptions, and lower entity ability conceptions were statistically correlated to lower (more availing) beliefs in the simple-integration and stable-expertise of knowledge. This reflects significant associations in PE and other domains between students' beliefs about knowledge (epistemology), the need for cognition, and educational outcomes like reasoning, motivation, the use of learning strategies, and achievement (e.g., Kardash \& Scholes, 1996; Lodewyk, 2009b; Lodewyk \& Sullivan, 2010). In order to encourage more students to learn and perform, it would 
seem logical for teachers to believe that student ability is malleable on the basis of effort and cognitive engagement, and that knowledge for PE is not simple, stable, or simply taught directly from their own expertise, but might be learned as, or more effectively, using more indirect and autonomous methods such as Teaching Games for Understanding (Rovegno, 2003). For example, Lee (1996) found that teachers who view students' ability as incremental were more prone to providing feedback based on effort rather than achievement, assign tasks for personal mastery rather than for public performance, and group students more heterogeneously rather than based on their perceptions of their ability. Further, teachers having a more sophisticated and accurate understanding of the complexity and evolving nature of knowledge in physical education might be prone to passing on that awareness to their students with corresponding changes in achievement-related behaviours (Rovegno, 2003). This study provides new insight into the nature of such relations among secondary physical educators.

\section{References}

Bandura, A. (1986). Social foundations of thought and action: A social cognitive theory. Englewood Cliffs, NJ: Prentice Hall.

Behets, D., \& Vergauwen, L. (2004). Value orientations in elementary and secondary physical education teachers in Flanders. Research Quarterly for Exercise and Sport, 75(2), 156164.

Biddle, S. J., Wang, J. C., Chatzisarantis, N. L., \& Spray, C. M. (2003). Motivation for physical activity in young people: Entity and incremental beliefs about athletic ability. Journal of Sport Sciences, 21, 973-989.

Butler, J. I. (2005). TGfU pet-agogy: Old dogs, new tricks and puppy school. Physical Education and Sport Pedagogy, 10, 225 - 240 .

Dodds, P., Griffin, L. L., \& Placek, J. H. (2001). A selected review of the literature on development of learners' domain-specific knowledge [Special Issue]. Journal of Teaching in Physical Education, 20, 301-313.

Dweck, C. S. (2002). The development of ability conceptions. In A. Wigfield \& J. S. Eccles (Eds.), Development of achievement motivation (pp. 57-88). New York: Academic Press.

Haggar, M. S., \& Chatzisarantis, N. L. (2007). The trans-contextual model of motivation. In M.S. Haggar \& N. L. Chatzisarantis (Eds.), Intrinsic motivation and self-determination in exercise and sport (pp. 53-70). Champaign, IL: Human Kinetics.

Hofer, B. K., \& Pintrich, P. R. (Eds.). (2002). Personal epistemology: The psychology of beliefs about knowledge and knowing. Mahwah, NJ: Lawrence Erlbaum.

Kardash, C. M., \& Scholes, R. J. (1996). Effects of pre-existing beliefs, epistemological beliefs, and need for cognition on interpretation of controversial issues. Journal of Educational Psychology, 88, 260-271.

Lee, K. (1996). A study of teacher responses based on their conceptions of intelligence. Journal of Classroom Interaction, 31, 1-12. 
Li, W., Lee, A. M., \& Solmon, M. A. (2005). Relationships among dispositional ability conceptions, intrinsic motivation, perceived competence, experience, persistence, and performance. Journal of Teaching in Physical Education, 24, 51-65.

Lodewyk, K. R. (2009a). Relations among beliefs about epistemology and value for TGfU in university students. In T. Hopper, J. Butler \& B. Storey (Eds.), TGfU... Simply good pedagogy: Understanding a complex challenge (pp. 207-216). Ottawa, ON: Physical and Health Education Canada.

Lodewyk, K. R. (2009b). Exploring relations among achievement and beliefs about epistemology and ability in high school physical education students. The Physical Educator, 66(3), 124-138.

Lodewyk, K. R., Gammage, K., \& Sullivan, P. (2009). Relations between body size discrepancy, gender, and indices of motivation and achievement in high school physical education. Journal of Teaching in Physical Education. 28(4), 362-377.

Lodewyk, K. R., \& Sullivan, P. (2010). Considering beliefs about epistemology, ability, and the need for cognition as achievement-related factors in university physical education students. Phenex, 2(2), 1-21.

Loewenthal, K. M. (1996). An introduction to psychological tests and scales. London: UCL Press Limited.

McPherson, S. L., \& Kernodle, M. W. (2003). Tactics, the neglected attribute of expertise. In J. L. Starkes \& K. A. Ericsson (Eds.), Expert performance in sports: Advances in research on sport expertise (pp. 137-167). Windsor, ON: Human Kinetics.

Metzler, M. W. (2000). Instructional models for physical education. Needham Heights, MA: Allyn \& Bacon.

Ntoumanis, N., Pensgaard, A. M., Martin, C., \& Pipe, K. (2004). An ideographic analysis of amotivation in compulsory school physical education. Journal of Sport \& Exercise

Psychology, 26, 197-214.

Ntoumanis, N. (2005). A prospective study of participation in optional school physical education using a self-determination theory framework. Journal of Educational Psychology, 97, 444-453.

Ommundsen, Y. (2003). Implicit theories of ability and self-regulation strategies in physical education classes. Educational Psychology, 23, 141-157.

Oslin, J. \& Mitchell, S. (2006). Game-centred approaches to teaching physical education. In D. Kirk, D. MacDonald \& M. O’Sullivan (Eds.), The handbook of physical education (pp. 627-651). London, England: Sage.

Rovegno, I. (2003). Teachers' knowledge construction. In S. J. Silverman \& C.D. Ennis (Eds.), Student learning in physical education: Applying research to enhance instruction $\left(2^{\text {nd }}\right.$ ed., pp. 295-310). Champaign, IL: Human Kinetics.

Ryan, R. M., \& Deci, E. L. (2000). Self-determination theory and the facilitation of intrinsic motivation, social development, and well being. American Psychologist, 55, 68-78.

Schraw, G. \& Olafson, L. (2002). Teachers' epistemological worldviews and educational practices. Issues in Education, 8(2), 99-149.

Standage, M., Duda, J. L., \& Ntoumanis, N. (2006). Students' motivational processes and their relationship to teacher ratings in school physical education: A self-determination theory approach. Research Quarterly for Exercise and Sport, 77, 100-110. 